\title{
REVIEW
}

\section{How thyroid tumors start and why it matters: kinase mutants as targets for solid cancer pharmacotherapy}

\author{
J A Fagin \\ Division of Endocrinology and Metabolism, University of Cincinnati College of Medicine, PO Box 670547, Cincinnati, Ohio 45267-0547, USA \\ (Requests for offprints should be addressed to J A Fagin; Email: James.Fagin@uc.edu) \\ This article was presented at a symposium jointly sponsored by Journal of Endocrinology and Clinical Endocrinology at the BES meeting in Brighton, UK, 22-24 \\ March 2004. Another paper from the same symposium has been published: Weetman AP 2004 Cellular immune responses in autoimmune thyroid disease. \\ Clinical Endocrinology 61 405-413. CrossRef (http://dx.doi.org/10.1111/j.1365-2265.2004.02085.x).
}

\begin{abstract}
Treatment of patients with thyroid cancer is usually successful, and most patients are cured of the disease. However, we do not have effective therapies for patients with invasive or metastatic thyroid cancer if the disease is not surgically resectable and does not concentrate radioiodine. Conventional external beam radiotherapy and chemotherapy are of marginal benefit. In other types of cancer, new therapies are being developed that take advantage of our knowledge of cancer pathogenesis to interfere with the activity of specific oncoproteins believed to be important in disease causation. Because these approaches are being considered for thyroid cancer, I will briefly describe in this review examples of recent breakthroughs in medical therapy of certain hematological malignancies and some solid tumors using drugs that work
\end{abstract}

in this fashion, focusing in particular on compounds that block the enzymatic activity of specific tyrosine kinase oncoproteins. It should be noted, however, that cancers commonly harbor mutations or other disruptions of many genes, each of which could conceivably play a role in disease pathogenesis. This makes the choice of molecular target a difficult and critical decision if these approaches are to succeed. Here I will argue that priority should be given to blocking the function of oncoproteins activated early in tumor development. We have a fairly good understanding of the genetic changes involved in thyroid cancer initiation, and hence these cancers may prove to be particularly well suited for oncoprotein-specific therapies. Journal of Endocrinology (2004) 183, 249-256

\section{The emerging field of targeted cancer therapies}

Targeted cancer therapies attempt to disrupt pathways that are inappropriately activated in cancer cells while leaving normal cells relatively unscathed. Although we still have limited clinical experience with these agents, there has been enough time to draw some useful conclusions. The most notable initial success has been with Gleevec (imanitib) in Philadelphia chromosome/BCR-ABL (+) chronic myelogenous leukemia (CML) (Druker et al. 2001). The $B C R-A B L$ translocation results in expression of a BCR-ABL fusion protein, leading to constitutive activation of abl kinase activity and unregulated proliferation and survival of a primitive hematopoietic cell clone. Imanitib is a relatively selective inhibitor of abl kinase, and induces high rates of remission in patients with CML. Imanitib is also effective in patients with gastrointestinal stromal tumors, which are associated with activating mutations of the tyrosine kinase (TK) receptor C-KIT (Heinrich et al. 2000, Joensuu et al. 2001), and for metastatic dermatofibrosarcoma protuberans, believed to be dependent on the activity of the platelet-derived growth factor receptor kinase. In both cases, imanitib has been shown to have potent inhibitory activity on the activity of these receptor kinases, likely explaining the beneficial effects in patients with these conditions. Another success story in targeted therapies is that of patients with acute promyelocytic leukemia associated with a chromosomal translocation leading to expression of the PML-RAR $\alpha$ fusion protein, leading to overexpression of the retinoic acid receptor $\alpha$. A significant proportion of these patients respond well to treatment with all-trans retinoic acid (ATRA) (Fenaux et al. 2000). Despite these favorable results, numerous other compounds have failed at early phases of clinical development, dampening some of the initial enthusiasm with targeted therapies 
(Katsnelson 2004). Some of the difficulties encountered likely stemmed from inappropriate choice of molecular targets, undesirable side effects or problems with trial design.

\section{Target selection: role of tumor-initiating events}

A notable feature of some of the early successes in targeted therapies is that compounds such as imanitib and ATRA inhibit the activity of gene products believed to be early events in tumorigenesis. Thus, BCR-ABL and PML$R A R \alpha$ are thought to occur early in leukemogenesis (Brown et al. 1997). Their central role in leukemia development is demonstrated by their ability to induce myeloid proliferation when selectively overexpressed in myelocytes of transgenic mice. Recent studies in patients with CML who developed resistance to treatment with the abl kinase inhibitor imanitib showed that many of these had selected and/or acquired tumor clones with point mutations coding for substitutions within the imanitib-binding pocket of $\mathrm{BCR}-\mathrm{ABL}$, which interfered with binding and conferred resistance to the antagonist (Hochhaus et al. 2002, Shah et al. 2002). This illustrates two important points. First, that when placed under selective pressure, CML has potential for recurrence by reactivating the same pathway involved in tumor development (i.e. abl kinase activation) through acquisition of new somatic mutations. Secondly, that the abl kinase is indeed a major driving influence required for survival and expansion of the tumor clone. Because of these considerations, it is possible that oncoproteins implicated in tumor initiation may be particularly well suited as targets for development of inhibitory compounds. This is not to say that interfering with initiation events is all that will be needed, since it may ultimately be necessary to use combination therapies to block multiple pathways. We propose that oncoproteins activated by tumor-initiating mutations are likely to remain essential drivers of tumor expansion even after accumulation of numerous additional genetic changes. This premise, which has major implications for the potential effectiveness of targeted therapies, remains to be proven as a general principle, and in specific tumor types.

\section{Tumor-initiation events in thyroid cancer: the RET/PTC oncogenes}

Thyroid cancers stand out among solid tumors because many of the tumor-initiating genetic events have been identified. Notable among them are the RET/PTC oncogenes, which are believed to play a causative role in the pathogenesis of a significant proportion of papillary carcinomas of the thyroid (PTC), in particular those arising after radiation exposure, and in pediatric cancers. Chromosomal rearrangements linking the promoter and $\mathrm{N}$-terminal domains of unrelated gene/s to the C-terminal fragment of RET result in the aberrant production of a chimeric form of the receptor in thyroid cells that is constitutively active (Santoro et al. 2002). Several forms have been identified that differ according to the $5^{\prime}$ partner gene involved in the rearrangement, with RET/PTC1 and RET/PTC3 being the most common. RET/PTC1 is formed by a paracentric inversion of the long arm of chromosome 10 leading to fusion of RET with a gene named H4/D10S170. RET/PTC3 is also a result of an intrachromosomal rearrangement and is formed by fusion with the RFG/ELE1 gene. Multiple lines of evidence point to RET/PTC as one of the key first steps in thyroid cancer pathogenesis (Fig. 1): (i) Thyroid-specific overexpression of either RET/PTC1 (Jhiang et al. 1996, Santoro et al. 1996) or RET/PTC3 (Powell et al. 1998) in transgenic mice leads to development of tumors with histological features consistent with papillary thyroid carcinoma, indicating that these oncoproteins can recreate the disease in an animal model. (ii) There is a high prevalence of RET/PTC expression in occult or microscopic PTC (Viglietto et al. 1995, Sugg et al. 1998, Corvi et al. 2001), pointing to the activation of this oncogene at early stages of tumor development. (iii) Exposure of cell lines (Ito et al. 1993) and fetal thyroid explants (Mizuno et al. 1997) to ionizing radiation results in expression of RET/PTC within hours, supporting a direct role for radiation in the illegitimate recombination of RET. (iv) The breakpoints in the RET and ELE1/RFG genes resulting in the RET/PTC3 rearrangements of radiationinduced pediatric thyroid cancers from Chernobyl are consistent with direct double-strand DNA break resulting in illegitimate reciprocal recombination (Nikiforov et al. 1999). Moreover, the $H 4$ and RET genes, although lying at a considerable linear distance from each other within chromosome 10, are spatially juxtaposed during interphase in thyroid cells and presumably present a target for simultaneous double-strand breaks in each gene after ionizing radiation, thus giving rise to the RET/PTC1 rearrangement (Nikiforova et al. 2000). These data provide evidence that ionizing radiation, the major risk factor for development of papillary thyroid cancer, can directly induce RET recombination events, and link environmental events to tumor initiation through this genetic pathway.

\section{Mapping of signaling pathways used by RET/PTC to induce thyroid cell transformation provides clues for discovery of new thyroid oncogene}

The RET/PTC rearrangements result in illegitimate expression of chimeric proteins consisting of an $\mathrm{N}$-terminal fragment donated by one of the heterologous gene partners, fused to the intracellular TK domain of RET. The fusion proteins dimerize in a ligand-independent manner due to motifs present in the N-terminal domains. This results in 


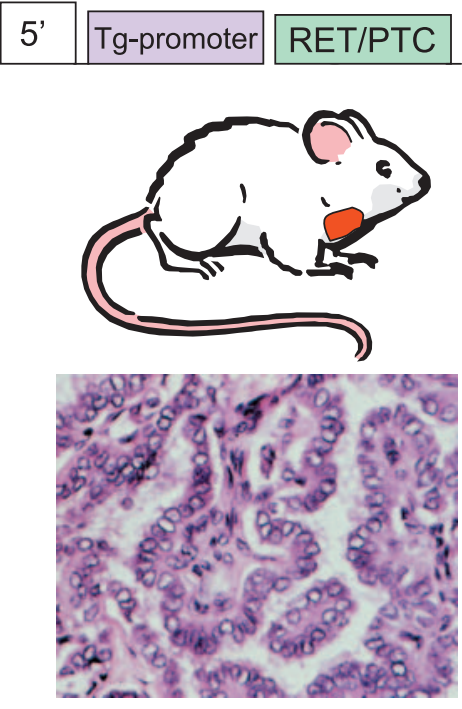

A

\section{$3^{\prime}$}

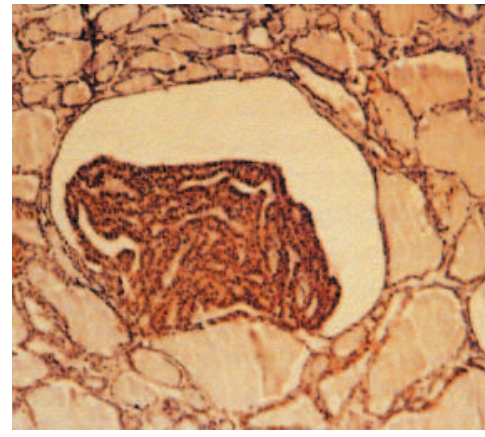

$\mathrm{B}$
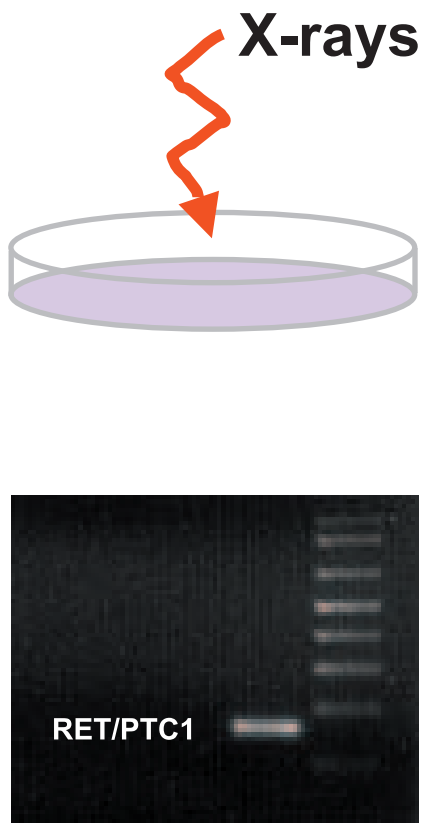

$\mathrm{C}$

Figure 1 RET/PTC rearrangements are involved in papillary thyroid carcinoma initiation. Several lines of evidence support the concept that RET/PTC is an early genetic event predisposing to development of papillary thyroid cancer. (A) Thyroid-specific expression of RET/PTC1 (Jhiang et al. 1996, Santoro et al. 1996) or RET/PTC3 (Powell et al. 1998) in transgenic mice result in development of tumors with cellular features resembling papillary thyroid carcinoma. (B) RET/PTC expression is detected in human thyroid micropapillary carcinomas (Viglietto et al. 1995, Sugg et al. 1998, Corvi et al. 2001). (C) External irradiation of human thyroid fetal explants and human carcinoma cell lines results in detectable RET/PTC rearrangements after short time intervals (Ito et al. 1993). Elements of this Figure are reproduced with permission from Powell et al. (1998) and Corvi et al. (2001).

constitutive activation of the TK function of RET, autophosphorylation at selected tyrosine residues, and initiation of intracellular signaling by engagement with effectors through specific tyrosine-phosphorylated domains of the receptor. Three RET protein variants (RET9, RET43 and RET51) have been shown to be generated by alternative splicing. They have identical primary structures until amino acid 1063, followed by unique C-terminal sequences (Myers et al. 1995). Three sites of tyrosine phosphorylation are common to all these variants, and have been shown to function as docking sites for signaling molecules. $p \mathrm{Y} 905$ mediates the recruitment of the SH2 domain-containing proteins Grb7 and Grb10. Phospholipase $\mathrm{C} \gamma$ associates with RET via pY1015 (Borrello et al. 1996), and Shc and Frs2 interact with pY1062 (Arighi et al. 1997, De Vita et al. 2000, Melillo et al. 2001). Regardless of its phosphorylation state, Y1062 also interacts with the Enigma protein, which targets RET/PTC isoforms to the inner surface of the plasma membrane (Durick et al. 1998). Several investigators have explored the contribution of signaling effector pathways activated via Y1062 of RET on cell growth and transformation, primarily in NIH3T3 cells and in the rat pheochromocytoma cell line PC12 (Asai et al. 1996, De Vita et al.
2000, Segouffin-Cariou \& Billaud 2000). In these cells, RET-Y1062, acting via either PI3K or MAPK, is required for the effects of RET on cell transformation, survival and migration. In thyroid follicular cells, RET/ PTC requires Y1062 (for clarity, amino acid numbering corresponds to that of wild-type RET) to activate ShcRas-Raf-Mek-Erk, and this pathway is in turn required for RET/PTC-dependent stimulation of DNA synthesis (Knauf et al. 2003).

Buckwalter et al. (2002) investigated the contribution of these signaling pathways to RET/PTC1-induced thyroid tumor formation in vivo by characterizing transgenic mice expressing thyroid-targeted RET/PTC1 mutants with phenylalanine substitutions at either Y905, Y1015 or Y1062. Tumor formation was significantly decreased in all of the mutants, but in particular by RET/PTC1 Y905F. This points to significant contributions mediated by all of these pathways to RET/PTC-induced thyroid cell transformation. The interpretation of these experiments is complicated by the fact that RET/PTC expression in thyroid cells causes primary hypothyroidism through impaired expression of many of the specialized proteins required for thyroid hormonogenesis, and the degree of hypothyroidism and of the consequent thyrotropin 


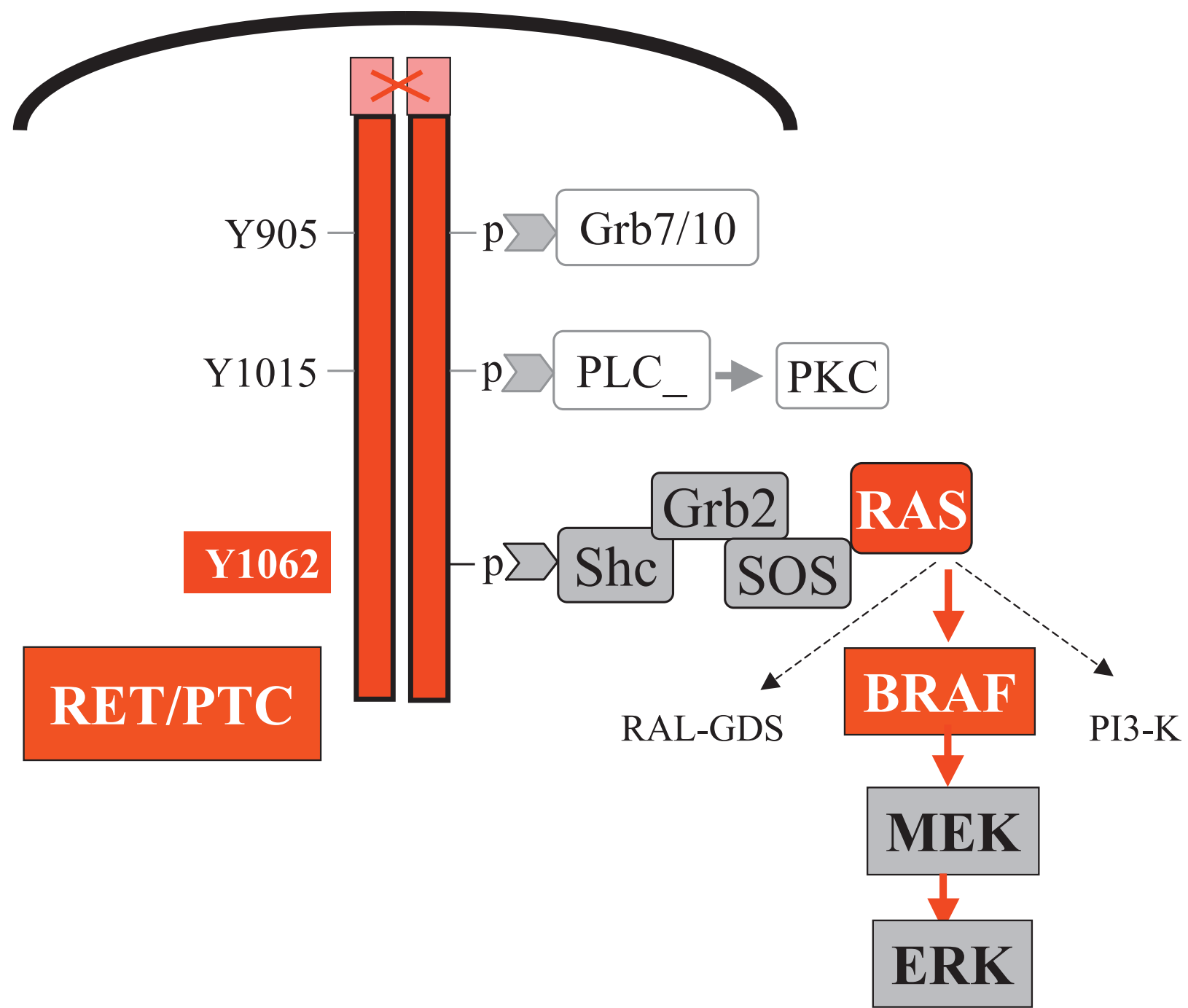

Figure 2 Mutations of three genes that signal in tandem implicate constitutive activation of the Ras-RAF-MAP kinase pathway in PTC pathogenesis. Several in vitro studies point to a critical role of RET Y1062, signaling via Ras and Raf, in cell transformation and thyroid cell dedifferentiation. Recent analysis of human papillary thyroid cancers demonstrate the presence of mutually exclusive mutations of either RET/PTC, RAS or BRAF, with little overlap between them, providing compelling genetic evidence for the critical role of this pathway in pathogenesis of these cancers.

elevation may have varied in severity between the mice expressing the different RET/PTC mutants. Nevertheless, this study indicates that none of these RET/PTC tyrosine residues alone is absolutely required for tumor formation, and all appear to contribute to some extent to the ultimate phenotype.

By contrast, in vitro data in thyroid cells point to an absolute requirement of Y1062 for RET/PTC-induced dedifferentiation, as determined by decreased expression of thyroid-specific gene products such as the sodium iodide symporter, thyroglobulin or PAX-8. RET/PTC-mediated dedifferentiation requires activation of Shc-RAS-RAFMAP kinase (Knauf et al. 2003), thus providing a good rationale to explore the contribution of mutations of other effectors in this pathway to thyroid cancer pathogenesis (Fig. 2).

\section{B-RAF: the most prevalent thyroid oncogene}

There are three isoforms of the serine-threonine kinase Raf in mammalian cells: A-Raf, B-Raf, and C-Raf or Raf1. C-Raf is expressed ubiquitously, whereas B-Raf is expressed at higher levels in hemopoietic cells, neurons and testis (Daum et al. 1994). B-Raf is also the predominant isoform in thyroid follicular cells (L Zhang, $\mathrm{N}$ 
Mitsutake, J A Knauf \& J A Fagin, unpublished observations). Although all Raf isoforms activate MEK phosphorylation, they are differentially activated by oncogenic Ras. In addition, B-R af has higher affinity for MEK1 and MEK2 and is more efficient in phosphorylating MEKs than other Raf isoforms (Peyssonnaux \& Eychene 2001). $B R A F$ somatic mutations were recently reported in a high proportion of benign nevi (Pollock et al. 2003) and malignant melanomas (Davies et al. 2002), and in a smaller subset of colorectal and ovarian cancers (Davies et al. 2002). A total of $98 \%$ of the mutations in melanomas resulted from thymine-to-adenine transversions at nucleotide position 1796, resulting in a valine-to-glutamate substitution at residue 600 (V600E), formerly designated as V599E. Recent resolution of the crystal structure of the wild-type and B-Raf V600E kinase domains helps understand the mechanisms of mutational activation of the protein (Wan et al. 2004). B-Raf exhibits the characteristic bilobar structure of protein kinases. In its inactive conformation, B-Raf residues G596-V600 in the activation loop form hydrophobic interactions with residues G464-V471 in the ATP-binding site (P loop), resulting in a structure that is not aligned for binding to ATP or substrate. Oncogenic mutations in the activation loop or the P loop disrupt their interaction and destabilize the inactive conformation. Most, but not all of known oncogenic B-Raf substitutions allow the formation of new interactions that fold the kinase into a catalytically competent structure (Dhillon \& Kolch 2004). Paradoxically, some of the oncogenic Braf mutants impair in vitro kinase activity (Wan et al. 2004). Despite this, these low-activity kinase Braf mutants induce ERK phosphorylation, which is due to activation of Raf1, presumably by heterodimerization (Wan et al. 2004).

The BRAFT1796A mutation is the most common genetic change in PTC, and present in about $36-69 \%$ of cases (Cohen et al. 2003, Fukushima et al. 2003, Kimura et al. 2003, Namba et al. 2003, Nikiforova et al. 2003, Soares et al. 2003, Xu et al. 2003, Trovisco et al. 2004). $B R A F^{T 1796 A}$ mutations are unique to PTC, and not found in any other form of well-differentiated follicular neoplasm arising from the same cell type. There is practically no overlap between PTC with RET/PTC, BRAF or RAS mutations, which altogether are found in about $70 \%$ of cases (Kimura et al. 2003, Soares et al. 2003). The lack of concordance for these mutations provides compelling genetic evidence for the requirement of this signaling system for transformation to PTC (Fig. 2). As these signaling proteins function along the same pathway in thyroid cells, this represents a unique paradigm of human tumorigenesis through mutation of three signaling effectors lying in tandem (Fig. 2). BRAF mutations can occur early in development of PTC, based on evidence that they are present in microscopic PTC (Nikiforova et al. 2003). Moreover, PTC with BRAF mutations have more aggressive properties, present more often with extrathyroidal invasion and at a more advanced clinical stage. The tall-cell variant papillary thyroid cancers, widely regarded as more aggressive, have a particularly high prevalence of BRAF mutations (Nikiforova et al. 2003). Undifferentiated or anaplastic carcinomas arising from preexisting papillary thyroid cancers have a significant prevalence of $B R A F$ mutations, whereas those arising from preexisting follicular carcinoma do not (Namba et al. 2003, Nikiforova et al. 2003). These data indicate that BRAF mutations may be an alternative tumor-initiating event in papillary thyroid cancer, and that tumors with this genotype carry a less favorable prognosis. The role of oncogenic Braf as a tumor-initiating event has been confirmed in mice with targeted expression of BRAFV600E in thyroid cells. These animals develop papillary thyroid cancers with high penetrance early in life, and progress to dedifferentiation, capsular and microvascular invasion, confirming many of the features found in the human tumors (J A Knauf, N Mitsutake, L Zhang, Y E Nikiforov \& J A Fagin, unpublished observations).

\section{Small molecule kinase inhibitors in thyroid cancer}

Protein kinases are involved in transmitting intracellular signals that eventuate in all biological properties of cancer cells, including growth, survival, motility, invasion and metastasis. It is no surprise that these signaling effectors have been considered prime targets for interference by anticancer therapies. This approach, initially greeted with skepticism because of concerns of lack of specificity due to common catalytic mechanisms and structural similarity between kinases, has now shown clinical value with the emergence of the abl kinase inhibitor imanitib. Most of the protein kinase antagonists in development are directed towards the ATP-binding site. However, there are other potential approaches to inhibit specific kinases, by interfering with expression of the kinase, folding of the mature protein or interaction with substrates (Dancey \& Sausville 2003). Among solid cancers, thyroid carcinomas represent a particularly promising paradigm for targeted therapy because some of the key oncogenic events are activating mutations of genes coding for TKs, and these occur early in cancer development.

RET is a logical target for selective inhibition in both medullary and papillary thyroid cancers. Several groups have published preclinical studies with compounds showing inhibitory effects on RET kinase activity at low nanomolar concentrations, and impairment of cell growth in vitro and in mouse xenografts (Carlomagno et al. 2002a,b, 2003, Lanzi et al. 2003, Strock et al. 2003) (Table 1). At least one of these compounds, ZD6474, originally developed as an anti-angiogenic agent through its inhibition of the vascular endothelial growth factor receptor KDR (Hartman et al. 2002), is now entering clinical trials for patients with medullary thyroid cancer. 
Table 1 Selected RET and Raf small molecule kinase inhibitors

\begin{tabular}{|c|c|c|c|c|}
\hline & Agent & Structure & IC50 & Reference \\
\hline \multicolumn{5}{|c|}{ Target } \\
\hline \multirow[t]{6}{*}{ RET } & RPI-1 & 2-Indolinone & $20-40 \mu \mathrm{M}$ & Lanzi et al. (2000) \\
\hline & PP1 & Pyrazolopyrimidine & $80 \mathrm{nM}$ & Carlomagno et al. (2002b) \\
\hline & PP2 & Pyrazolopyrimidine & $100 \mathrm{nM}$ & Carlomagno et al. (2003) \\
\hline & ZD $6474^{1}$ & Quinazoline & $100 \mathrm{nM}$ & Carlomagno et al. (2002a) \\
\hline & CEP-7012 & Indolocarbazole & $<100 \mathrm{nM}$ & Strock et al. (2003) \\
\hline & CEP-751 & Indolocarbazole & $<100 \mathrm{nM}$ & Strock et al. (2003) \\
\hline \multirow[t]{2}{*}{ RAF } & BAY $43-9006^{3}$ & Bis-aryl urea & $12 \mathrm{nM}(\operatorname{Raf} 1)$ & Lyons et al. (2001) \\
\hline & $\mathrm{L}-779,450^{4}$ & Triarylimidazole & $1 \mu \mathrm{M}$ & Shelton et al. (2003) \\
\hline
\end{tabular}

${ }^{1}$ Astra Zeneca; ${ }^{2}$ Cephalon; ${ }^{3}$ Bayer/Onyx; ${ }^{4}$ Merck.

B-Raf represents an attractive target for treatment of papillary thyroid cancers because of its possible role in tumor initiation, its high prevalence, and its association with tumors presenting at an advanced stage. The compound BAY43-9006 is a potent and effective Raf inhibitor in vitro and in mouse xenografts, and is presently in clinical trials for other forms of cancer (Karasarides et al. 2004). Other Raf inhibitors, in the form of small molecule kinase inhibitors as well as antisense oligonucleotides, are also in development (Dancey \& Sausville 2003). In due course it is likely that at least one of these compounds or others with similar properties will be tested in patients with advanced papillary thyroid cancer. It should be noted that other signaling pathways and molecular targets (Braga-Basaria et al. 2004), although not directly activated through genetic mutations, may prove to be crucial for thyroid cancer progression and thus appropriate for targeted inhibition.

\section{Conclusions}

We are finally seeing the emergence of new approaches for development of thyroid cancer therapies, and there is reason for optimism that we may soon have new options for our patients. A note of caution is still in order. The activity of the oncogenic kinases may no longer be required once the tumors have progressed to highly malignant cancers and accumulated numerous other genetic changes. Some have suggested that at least some thyroid cancers may not be entirely clonal for the mutated kinase, raising the prospect of resistance to therapy. The latter can also take place through somatic development of new mutations within the respective kinase genes, rendering the oncoproteins resistant to the inhibitory compounds. Certain mutations of $B C R-A B L$, including some resulting in substitutions within the imanitib-contact sites in the ATP-binding pocket, have been associated with imanitib resistance and CML recurrence (Hochhaus et al. 2002, Shah et al. 2002). In the case of RET, an oncogenic point mutation in codon 804 present in some patients with MEN2 is associated with resistance to many of the known RET antagonists (Carlomagno et al. 2004). Finally, inhibition of kinase activity may induce cytostatic effects rather than cell death, and/or require co-administration of other therapies for beneficial effects to manifest.

\section{Funding}

This paper was supported in part by NIH grant CA50706. The author declares that there is no conflict of interest that would prejudice the impartiality of this scientific work.

\section{Acknowledgements}

I am grateful to my fellows and other collaborators for contributing to many aspects of the original work which forms the basis for the topics discussed in this review, and in particular to Efisio Puxeddu for designing the graphics of Fig. 1.

\section{References}

Arighi E, Alberti L, Torriti F, Ghizzoni S, Rizzetti MG, Pelicci G, Pasini B, Bongarzone I, Piutti C, Pierotti MA et al. 1997

Identification of Shc docking site on Ret tyrosine kinase. Oncogene 14 773-782.

Asai N, Murakami H, Iwashita T \& Takahashi M 1996 A mutation at tyrosine 1062 in MEN2A-Ret and MEN2B-Ret impairs their transforming activity and association with she adaptor proteins. Journal of Biological Chemistry 271 17644-17649.

Borrello MG, Alberti L, Arighi E, Bongarzone I, Battistini C, Bardelli A, Pasini B, Piutti C, Rizzetti MG, Mondellini P et al. 1996 The full oncogenic activity of Ret/ptc2 depends on tyrosine 539 , a docking site for phospholipase Cgamma. Molecular and Cellular Biology 16 2151-2163.

Braga-Basaria M, Hardy E, Gottfried R, Burman KD, Saji M \& Ringel MD 2004 17-Allylamino-17-demethoxygeldanamycin activity against thyroid cancer cell lines correlates with heat shock protein 90 levels. Journal of Clinical Endocrinology and Metabolism 89 2982-2988. 
Brown D, Kogan S, Lagasse E, Weissman I, Alcalay M, Pelicci PG, Atwater S \& Bishop JM 1997 A PMLRARalpha transgene initiates murine acute promyelocytic leukemia. PNAS 94 2551-2556.

Buckwalter TL, Venkateswaran A, Lavender M, La Perle KM, Cho JY, Robinson ML \& Jhiang SM 2002 The roles of phosphotyrosines-294, -404, and -451 in RET/PTC1-induced thyroid tumor formation. Oncogene 21 8166-8172.

Carlomagno F, Vitagliano D, Guida T, Ciardiello F, Tortora G, Vecchio G, Ryan AJ, Fontanini G, Fusco A \& Santoro M 2002a ZD6474, an orally available inhibitor of KDR tyrosine kinase activity, efficiently blocks oncogenic RET kinases. Cancer Research 62 7284-7290.

Carlomagno F, Vitagliano D, Guida T, Napolitano M, Vecchio G, Fusco A, Gazit A, Levitzki A \& Santoro M $2002 b$ The kinase inhibitor PP1 blocks tumorigenesis induced by RET oncogenes. Cancer Research 62 1077-1082.

Carlomagno F, Vitagliano D, Guida T, Basolo F, Castellone MD, Melillo RM, Fusco A \& Santoro M 2003 Efficient inhibition of RET/papillary thyroid carcinoma oncogenic kinases by 4-amino-5-(4-chloro-phenyl)-7-(t-butyl)pyrazolo[3,4-d]pyrimidine (PP2). Journal of Clinical Endocrinology and Metabolism 88 1897-1902.

Carlomagno F, Guida T, Anaganti S, Vecchio G, Fusco A, Ryan AJ, Billaud M \& Santoro M 2004 Disease associated mutations at valine 804 in the RET receptor tyrosine kinase confer resistance to selective kinase inhibitors. Oncogene 23 6056-6063.

Cohen Y, Xing M, Mambo E, Guo Z, Wu G, Trink B, Beller U, Westra WH, Ladenson PW \& Sidransky D 2003 BRAF mutation in papillary thyroid carcinoma. Journal of the National Cancer Institute 95 625-627.

Corvi R, Martinez-Alfaro M, Harach HR, Zini M, Papotti M \& Romeo G 2001 Frequent RET rearrangements in thyroid papillary microcarcinoma detected by interphase fluorescence in situ hybridization. Laboratory Investigation 81 1639-1645.

Dancey J \& Sausville EA 2003 Issues and progress with protein kinase inhibitors for cancer treatment. Nature Reviews. Drug Discovery 2 296-313.

Daum G, Eisenmann-Tappe I, Fries HW, Troppmair J \& Rapp UR 1994 The ins and outs of Raf kinases. Trends in Biochemical Sciences $19474-480$.

Davies H, Bignell GR, Cox C, Stephens P, Edkins S, Clegg S, Teague J, Woffendin H, Garnett MJ, Bottomley W et al. 2002 Mutations of the BRAF gene in human cancer. Nature 417 949-954.

De Vita G, Melillo RM, Carlomagno F, Visconti R, Castellone MD, Bellacosa A, Billaud M, Fusco A, Tsichlis PN \& Santoro M 2000 Tyrosine 1062 of RETMEN2A mediates activation of Akt (protein kinase $\mathrm{B}$ ) and mitogen-activated protein kinase pathways leading to PC12 cell survival. Cancer Research 60 3727-3731.

Dhillon AS \& Kolch W 2004 Oncogenic B-Raf mutations: crystal clear at last. Cancer Cell 5 303-304.

Durick K, Gill GN \& Taylor SS 1998 Shc and Enigma are both required for mitogenic signaling by Ret/ptc2. Molecular and Cellular Biology 18 2298-2308.

Druker BJ, Sawyers CL, Kantarjian H, Resta DJ, Reese SF, Ford JM, Capdeville R \& Talpaz M 2001 Activity of a specific inhibitor of the $\mathrm{BCR}-\mathrm{ABL}$ tyrosine kinase in the blast crisis of chronic myeloid leukemia and acute lymphoblastic leukemia with the Philadelphia chromosome. New England Journal of Medicine 344 1038-1042.

Fenaux P, Chevret S, Guerci A, Fegueux N, Dombret H, Thomas X, Sanz M, Link H, Maloisel F, Gardin C et al. 2000 Long-term follow-up confirms the benefit of all-trans retinoic acid in acute promyelocytic leukemia. European APL group. Lenkemia 14 1371-1377.

Fukushima T, Suzuki S, Mashiko M, Ohtake T, Endo Y, Takebayashi Y, Sekikawa K, Hagiwara K \& Takenoshita S 2003 BRAF mutations in papillary carcinomas of the thyroid. Oncogene 22 6455-6457.
Hartman GD, Fraley ME \& Bilodeau MT 2002 Kinase insert domain-containing receptor kinase inhibitors as anti-angiogenic agents. Expert Opinion in Investigational Drugs 11 737-745.

Heinrich MC, Griffith DJ, Druker BJ, Wait CL, Ott KA \& Zigler AJ 2000 Inhibition of c-kit receptor tyrosine kinase activity by STI 571, a selective tyrosine kinase inhibitor. Blood 96 925-932.

Hochhaus A, Kreil S, Corbin AS, La Rosee P, Muller MC, Lahaye T, Hanfstein B, Schoch C, Cross NC, Berger U et al. 2002 Molecular and chromosomal mechanisms of resistance to imanitib (STI571) therapy. Leukemia 16 2190-2196.

Ito T, Seyama T, Iwamoto KS, Hayashi T, Mizuno T, Tsuyama N, Dohi K, Nakamura N \& Akiyama M 1993 In vitro irradiation is able to cause RET oncogene rearrangement. Cancer Research $\mathbf{5 3}$ 2940-2943.

Jhiang SM, Sagartz JE, Tong Q, Parker-Thornburg J, Capen CC, Cho JY, Xing S \& Ledent C 1996 Targeted expression of the ret/PTC1 oncogene induces papillary thyroid carcinomas. Endocrinology 137 375-378.

Joensuu H, Roberts PJ, Sarlomo-Rikala M, Andersson LC, Tervahartiala P, Tuveson D, Silberman S, Capdeville R, Dimitrijevic S, Druker B et al. 2001 Effect of the tyrosine kinase inhibitor STI571 in a patient with a metastatic gastrointestinal stromal tumor. New England Journal of Medicine 344 1052-1056.

Karasarides M, Chiloeches A, Hayward R, Niculescu-Duvaz D, Scanlon I, Friedlos F, Ogilvie L, Hedley D, Martin J, Marshall CJ et al. $2004 \mathrm{~B}-\mathrm{RAF}$ is a therapeutic target in melanoma. Oncogene 23 6292-6298.

Katsnelson A 2004 Experts call for smarter approach to targeted therapies. Nature Medicine 10764.

Kimura ET, Nikiforova MN, Zhu Z, Knauf JA, Nikiforov YE \& Fagin JA 2003 High prevalence of BRAF mutations in thyroid cancer: genetic evidence for constitutive activation of the RET/PTC-RAS-BRAF signaling pathway in papillary thyroid carcinoma. Cancer Research 63 1454-1457.

Knauf JA, Kuroda H, Basu S \& Fagin JA 2003 RET/PTC-induced dedifferentiation of thyroid cells is mediated through Y1062 signaling through SHC-RAS-MAP kinase. Oncogene 22 4406-4412.

Lanzi C, Cassinelli G, Pensa T, Cassinis M, Gambetta RA, Borrello MG, Menta E, Pierotti MA \& Zunino F 2000 Inhibition of transforming activity of the ret/ptc1 oncoprotein by a 2-indolinone derivative. International Journal of Cancer 85 384-390.

Lanzi C, Cassinelli G, Cuccuru G, Zaffaroni N, Supino R, Vignati S, Zanchi C, Yamamoto M \& Zunino F 2003 Inactivation of Ret/Ptc1 oncoprotein and inhibition of papillary thyroid carcinoma cell proliferation by indolinone RPI-1. Cellular and Molecular Life Sciences 60 1449-1459.

Lyons JF, Wilhelm S, Hibner B \& Bollag G 2001 Discovery of a novel Raf kinase inhibitor. Endocrine-Related Cancer 8 219-225.

Melillo RM, Santoro M, Ong SH, Billaud M, Fusco A, Hadari YR, Schlessinger J \& Lax I 2001 Docking protein FRS2 links the protein tyrosine kinase RET and its oncogenic forms with the mitogen-activated protein kinase signaling cascade. Molecular and Cellular Biology 21 4177-4187.

Mizuno T, Kyoizumi S, Suzuki T, Iwamoto KS \& Seyama T 1997 Continued expression of a tissue specific activated oncogene in the early steps of radiation-induced human thyroid carcinogenesis. Oncogene 15 1455-1460.

Myers SM, Eng C, Ponder BA \& Mulligan LM 1995 Characterization of RET proto-oncogene $3^{\prime}$ splicing variants and polyadenylation sites: a novel C-terminus for RET. Oncogene 11 2039-2045.

Namba H, Nakashima M, Hayashi T, Hayashida N, Maeda S, Rogounovitch TI, Ohtsuru A, Saenko VA, Kanematsu T \& Yamashita S 2003 Clinical implication of hot spot BRAF mutation, V599E, in papillary thyroid cancers. Journal of Clinical Endocrinology and Metabolism 88 4393-4397.

Nikiforov YE, Koshoffer A, Nikiforova M, Stringer J \& Fagin JA 1999 Chromosomal breakpoint positions suggest a direct role for 
radiation in inducing illegitimate recombination between the ELE1 and RET genes in radiation-induced thyroid carcinomas. Oncogene 18 6330-6334.

Nikiforova MN, Stringer JR, Blough R, Medvedovic M, Fagin JA \& Nikiforov YE 2000 Proximity of chromosomal loci that participate in radiation-induced rearrangements in human cells. Science $\mathbf{2 9 0}$ 138-141.

Nikiforova MN, Kimura ET, Gandhi M, Biddinger PW, Knauf JA, Basolo F, Zhu Z, Giannini R, Salvatore G, Fusco A et al. 2003 BRAF mutations in thyroid tumors are restricted to papillary carcinomas and anaplastic or poorly differentiated carcinomas arising from papillary carcinomas. Journal of Clinical Endocrinology and Metabolism 88 5399-5404.

Peyssonnaux C \& Eychene A 2001 The Raf/MEK/ERK pathway: new concepts of activation. Biology of the Cell 93 53-62.

Pollock PM, Harper UL, Hansen KS, Yudt LM, Stark M, Robbins CM, Moses TY, Hostetter G, Wagner U, Kakareka J et al. 2003 High frequency of BRAF mutations in nevi. Nature Genetics 33 19-20.

Powell DJJ, Russell J, Nibu K, Li G, Rhee E, Liao M, Goldstein M, Keane WM, Santoro M, Fusco A et al. 1998 The RET/PTC3 oncogene: metastatic solid-type papillary carcinomas in murine thyroids. Cancer Research 58 5523-5528.

Santoro M, Chiappetta G, Cerrato A, Salvatore D, Zhang L, Manzo G, Picone A, Portella G, Santelli G, Vecchio G et al. 1996 Development of thyroid papillary carcinomas secondary to tissue-specific expression of the RET/PTC1 oncogene in transgenic mice. Oncogene 12 1821-1826.

Santoro M, Melillo RM, Carlomagno F, Fusco A \& Vecchio G 2002 Molecular mechanisms of RET activation in human cancer. Annals of the New York Academy of Sciences 963 116-121.

Segouffin-Cariou C \& Billaud M 2000 Transforming ability of MEN2A-RET requires activation of the phosphatidylinositol 3-kinase/AKT signaling pathway. Journal of Biological Chemistry 275 3568-3576.

Shah NP, Nicoll JM, Nagar B, Gorre ME, Paquette RL, Kuriyan J \& Sawyers CL 2002 Multiple BCR-ABL kinase domain mutations confer polyclonal resistance to the tyrosine kinase inhibitor imatinib (STI571) in chronic phase and blast crisis chronic myeloid leukemia. Cancer Cell 2 117-125.
Shelton JG, Moye PW, Steelman LS, Blalock WL, Lee JT, Franklin RA, McMahon M \& McCubrey JA 2003 Differential effects of kinase cascade inhibitors on neoplastic and cytokine-mediated cell proliferation. Leukemia 17 1765-1782.

Soares P, Trovisco V, Rocha AS, Lima J, Castro P, Preto A, Maximo V, Botelho T, Seruca R \& Sobrinho-Simoes M 2003 BRAF mutations and RET/PTC rearrangements are alternative events in the etiopathogenesis of PTC. Oncogene 22 4578-4580.

Strock CJ, Park JI, Rosen M, Dionne C, Ruggeri B, Jones-Bolin S, Denmeade SR, Ball DW \& Nelkin BD 2003 CEP-701 and CEP-751 inhibit constitutively activated RET tyrosine kinase activity and block medullary thyroid carcinoma cell growth. Cancer Research 63 5559-5563.

Sugg SL, Ezzat S, Rosen IB, Freeman JL \& Asa SL 1998 Distinct multiple RET/PTC gene rearrangements in multifocal papillary thyroid neoplasia. Journal of Clinical Endocrinology and Metabolism 83 4116-4122.

Trovisco V, Vieira de Castro I, Soares P, Maximo V, Silva P, Magalhaes J, Abrosimov A, Guiu XM \& Sobrinho-Simoes M 2004 BRAF mutations are associated with some histological types of papillary thyroid carcinoma. Journal of Pathology 202 247-251.

Viglietto G, Chiappetta G, Martinez-Tello FJ, Fukunaga FH, Tallini G, Rigopoulou D, Visconti R, Mastro A, Santoro M \& Fusco A $1995 \mathrm{RET} / \mathrm{PTC}$ oncogene activation is an early event in thyroid carcinogenesis. Oncogene 11 1207-1210.

Wan PT, Garnett MJ, Roe SM, Lee S, Niculescu-Duvaz D, Good VM, Jones CM, Marshall CJ, Springer CJ, Barford D et al. 2004 Mechanism of activation of the RAF-ERK signaling pathway by oncogenic mutations of B-RAF. Cell 116 855-867.

Xu X, Quiros RM, Gattuso P, Ain KB \& Prinz RA 2003 High prevalence of BRAF gene mutation in papillary thyroid carcinomas and thyroid tumor cell lines. Cancer Research 63 4561-4567.

Received 7 July 2004

Accepted 16 August 2004

Made available online as an

Accepted Preprint 26 August 2004 